\title{
Debate e Investigación La acomodación del PH al Estado Autonómico. Normativa, jurisprudencia constitucional y doctrina (1978-2004)
}

Javier García Fernández

Catedrático de Derecho Constitucional. Universidad de Alicante

\section{Resumen}

A lo largo de este trabajo vamos a examinar cómo ha ido evolucionando el Derecho español del Patrimonio Histórico desde la Constitución de 1978. Para ello veremos, en primer lugar, qué características esenciales tenía dicho ordenamiento en el momento en que se promulgó la Constitución, y después examinaremos cómo se produce su evolución a partir de la propia Constitución, de los diecisiete Estatutos de Autonomía, de la Ley 16/1985, de 25 de junio, del Patrimonio Histórico Español, de las sentencias del Tribunal Constitucional que afectan a temas territoriales de la cultura y, en fin, de las propias Leyes autonómicas. Para entender mejor esta evolución la hemos dividido en tres periodos: el anterior a la aprobación de la Ley estatal de 1985; el que transcurre entre la aprobación de esta Ley y la sentencia constitucional 17/1991, de 31 de enero, que resolvió diversos recursos de inconstitucionalidad suscitados contra esta Ley; y, finalmente, el que va desde la publicación de estas sentencias hasta nuestros dias, periodo que se caracteriza por la aprobación de la mayoría de las Leyes autonómicas.

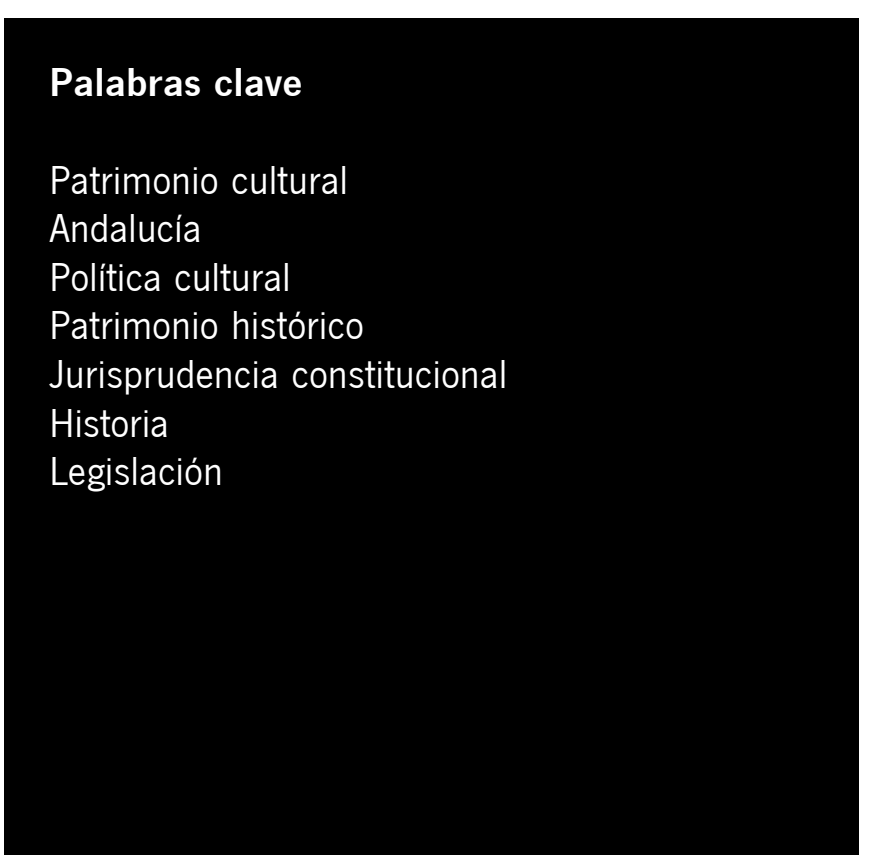

\section{Introducción}

Como ocurre con cualquier otra rama del ordenamiento jurídico, el Derecho vigente de los bienes culturales es el producto de una evolución que suele ser lenta salvo en momentos históricos muy significados en que se produce una aceleración por motivos generalmente políticos.

El Derecho español del Patrimonio Histórico ha seguido la misma evolución que el resto del ordenamiento. De ser un ordenamiento casi inexistente en el siglo XIX (Instrucción de 1803, Real Orden de 1837 sobre prohibición de salida de obras de arte, Real Orden de 1844 sobre Comisiones Provinciales de Monumentos, Ley Moyano de 1857, y poco más), su regulación se precipitó durante el siglo XX hasta producir grandes Leyes que han estado vigentes hasta hace menos de veinte años (Ley de Excavaciones de 1911, Real DecretoLey de 1926 sobre protección y conservación de la riqueza artística, Ley de 1933 sobre defensa, conservación y acrecentamiento del Patrimonio histórico-artístico nacional, Ley del Tesoro Documental y Bibliográfico de 1972). Sin embargo, incluso en la legislación producida durante la Segunda República, todo el Derecho del Patrimonio Histórico ha tenido una característica común y constante: era un ordenamiento producido por y para un Estado centralizado.

Por el contrario, el Derecho que se produce en España a partir de la entrada en vigor de la Constitución de 1978 responde a principios políticos y jurídicos contrapuestos: el Estado descentralizado en donde las unidades territoriales que lo componen, las Comunidades Autónomas, gozan de amplias competencias en multitud de materias, entre otras la cultura.

\section{La regulación jurídica del patrimonio} histórico al entrar en vigor la Constitución de 1978 y su distribución territorial

Como hemos apuntado más arriba, el Derecho del Patrimonio Histórico anterior a la Constitución de 1978 era un Derecho muy centralizado. Se trataba de un ordenamiento muy completo y de calidad aceptable, que abarcaba todas las áreas de lo que entonces se consideraba Patrimonio Artístico ${ }^{1}$ y que se fundaba en un modelo de gestión altamente centralizado. Esta centralización venía, en primer lugar, de la propia inexistencia de Comunidades Autónomas pero también de una filosofía que no permitía siquiera la menor desconcentración y que consideraba a la Administración Local (Diputaciones Provinciales y Ayuntamientos) como el último escalón de la Administración, sin el menor margen de autonomía.

Esta centralización, que en lo político fue impuesta por el régimen dictatorial que se implanta en 1939, y que en el campo de la gestión del Patrimonio Histórico coincide casi con los comienzos del siglo XX, es tanto más llamativa cuanto que la tradición española del siglo XIX había sido, quizá por necesidad, un tanto desconcentrada. La Real 


\section{$036-037$ \\ Debate \\ e Investigación}

La acomodación del PH

al Estado Autonómico.

Regulación normativa, etc.

\section{PH48 - Abril 2004}

Orden de 13 de junio de 1844, de creación de las Comisiones Provinciales de Monumentos, así como la Real Orden de 24 de julio del mismo año sobre atribuciones de la Sección Arqueológica de estas Comisiones, y el Real Decreto de 15 de noviembre de 1854 por el que se dio nueva organización a las Comisiones Central y Provinciales, para acabar con el Real Decreto de 24 de noviembre de 1865 por el que se aprueba el Reglamento de las Comisiones Provinciales de Monumentos (ligeramente retocado en 1881) comportaban, todas ellas, una gestión en cierto modo desconcentrada: la historia de los museos provinciales, como podemos seguir a través del gran libro de Gaya Nuño, es un ejemplo de la cierta autonomía de que gozó la Administración española de Bellas Artes durante el siglo XIX.

Curiosamente esta cierta desconcentración se quiebra en el siglo XX mucho antes del franquismo. Quizá porque la Administración de Bellas Artes se habia perfeccionado al crearse en 1901 la Dirección General del ramo, quizá por el avance de las comunicaciones terrestres, telegráficas y postales, lo cierto es que la legislación del siglo XX otorga más facultades a la Administración central: en la Ley de Excavaciones de 1911 y, sobre todo, en su Reglamento de 1912, desaparece prácticamente toda forma de gestión desconcentrada, desplazándose las principales facultades hacia la Junta Superior de Excavaciones y Antigüedades. Y en el Real Decreto-Ley de 9 de agosto de 1926 sobre protección y conservación de la riqueza artística, el protagonismo del Gobierno y del Ministerio del ramo era ya muy intenso si bien es cierto que en esta norma se detectaba, al menos, la actuación de la Administración periférica. Otro tanto, podemos decir, para no alargarnos, de la Ley de 13 de mayo de 1933 sobre defensa, conservación y acrecentamiento del Patrimonio histórico-artístico nacional, cuyo artículo tercero expresaba muy bien esta concepción centralizadora: "Compete a la Dirección General de Bellas Artes cuanto atañe a la defensa, conservación y acrecentamiento del patrimonio histórico-artístico nacional"
Esta trayectoria recentralizadora, entiéndase bien, no era en aquel momento criticable pues trataba de concentrar en un único Ministerio y en una única Dirección General todas las políticas públicas de protección de los bienes culturales. Era la respuesta moderna, y algo jacobina, a una benemérita Administración honorífica (la de las Comisiones de Monumentos) que habia agotado su eficacia.

Con estos antecedentes es fácil entender el modelo hipercentralizado establecido por el franquismo para la gestión del Patrimonio Histórico, modelo que estaba vigente cuando entró en vigor la Constitución de 1978. Sin poder precisar cifras, no nos equivocaremos si apuntamos que probablemente el $75 \%$ o el $80 \%$ de la gestión de los bienes de lo que se llamaba Patrimonio Artístico correspondia al Ministerio de Cultura, recientemente creado $^{2}$, a través principalmente de la Dirección General de Patrimonio Artístico, Archivos y Museos, que pronto entró en la vertiginosa carrera de cambios de denominación, y de tres Organismos Autónomos (el Patronato Nacional de Museos, el Patronato de la Alhambra y del Generalife y la Junta Coordinadora de Actividades y Establecimientos Culturales). Además, pocos meses después de crearse el nuevo Ministerio, el Real Decreto 392/1978, de 10 de febrero, estableció las Delegaciones Provinciales del Ministerio a las que estaban adscritos los Consejos Provinciales de Cultura y las Comisiones del Patrimonio Histórico-Artístico.

Además de esta doble organización, central y periférica, levantada a partir del nuevo Ministerio de Cultura, sólo se encontraban, en todo el ordenamiento, dos únicos atisbos de descentralización en favor de la entonces denominada Administración Local:

a) la Ley de Régimen Local (Texto Refundido aprobado por Decreto de 24 de junio de 1955), cuyo artículo 101.2.j) atribuia a los Municipios la protección de los Museos y de los monumentos artísticos

\section{Voces}

\section{De la primera Ley de patrimonio histórico a la Ley de Castilla y León}

\section{Enrique Saiz Martín}

Director General de Patrimonio y Bienes Culturales de la Junta de Castilla y León

La Constitución Española de 1978 introdujo una importante novedad para la regulación del patrimonio histórico, artístico y cultural, al establecer un marco descentralizado de organización territorial del Estado en el que se preveía la asunción por las Comunidades Autónomas de competencias en dicha materia en los términos que resultan de los artículos 148 y 149 . El último de estos preceptos reserva al Estado las competencias para la defensa del Patrimonio contra la exportación y la expoliación.
Como es bien conocido, a través de sus Estatutos de Autonomía todas las Comunidades han asumido, al amparo de estas previsiones de nuestra Constitución, competencias sobre patrimonio cultural con carácter exclusivo, esto es, con atribución de las potestades legislativa y reglamentaria y de la función ejecutiva, para cuyo ejercicio se establece como límite -no podria ser de otra manera- el respeto a lo dispuesto en la Constitución.

En el contexto de las disposiciones constitucionales y estatutarias mencionadas nace la Ley de Patrimonio Histórico Español de 25 de junio de 1985 (Ley 16/1985), en la que puede observarse cómo el legislador estatal procura la articulación de las competencias atribuidas al Estado y a las Comunidades Autónomas. La adecuación de la Ley 16/1985 a las previsiones de la Constitución fue objeto de verificación en la Sentencia del Tribunal Constitucional de 31 de enero de 1991 (número 17/1991), entre cuyos pronunciamientos se consagra el reconocimiento de la competencia autonómica para la declaración de Bienes de Interés Cultural, que ya 
e históricos, y el artículo 243.m) de la misma Ley que establecía la competencia provincial en materia de conservación de monumentos y de lugares artísticos e históricos;

b) la Ley de Régimen del Suelo y Ordenación Urbana (Texto refundido aprobado por Decreto 1346/1976, de 9 de abril) confería a los Planes Generales municipales de ordenación la inclusión de medidas para la defensa de los conjuntos históricos-artísticos [artículo 12.1.d)], en cuyo desarrollo se deberían redactar, si fuese necesario, Planes Especiales para la ordenación de recintos y conjuntos artísticos (artículo 17.1).

Este era el modelo centralizado de gestión del Patrimonio Histórico que regía en España cuando se aprobó la Constitución.

\section{El período 1978-1985. Desde la Constitución hasta la Ley del Patrimonio Histórico Español}

Este primer período post-constitucional se caracteriza, visto en conjunto, por varias circunstancias decisivas: a) la aparición de un modelo altamente descentralizado de gestión cultural a través de la Constitución; b) la trasposición de las previsiones constitucionales a los Estatutos de Autonomía; c) la ejecución del modelo descentralizador a través de las transferencias de funciones y servicios del Estados a favor de las Comunidades Autónomas e incluso de los Entes preautonómicos. Como consecuencia de estas circunstancias, y con efectos igualmente relevantes, se dio también: d) la adecuación de la Administración periférica del Estado, en el ramo de Cultura, a la nueva descentralización; e) la paralela creación de los servicios autonómicos de gestión cultural; f) las primeras Leyes y normas autonómicas que todavía no tenían vocación de regulación general de la materia; g) algunas sentencias del Tribunal Constitucional que empezaron a apuntar ideas sobre el reparto de competencias (para este aspecto, remitimos al artículo del profesor RuizRico, p. 63 y ss.); h) la aparición de los primeros trabajos de carácter doctrinal destinados a esclarecer la nueva situación.

\section{Aparición de un modelo altamente descentralizado de gestión cultural a través de la Constitución}

El nuevo modelo de distribución de competencias, conforme a una técnica que aparece ya en la Constitución mejicana de 1917 y se consolida en las Constituciones alemana de 1919 y austríaca de 1920 , se funda en establecer tres campos competenciales que corresponden, respectivamente, al Estado, a las Comunidades Autónomas más un tertium genus de cierta concurrencia.

La atribución al Estado de competencias en materia de Patrimonio Histórico se encuentra en el artículo 149.1.28 de la Constitución que establece que será de la competencia exclusiva del Estado la "defensa del patrimonio cultural, artístico y monumental español contra la exportación y la expoliación; museos, bibliotecas y archivos de titularidad estatal, sin perjuicio de su gestión por parte de las Comunidades Autónomas". Por el contrario, a las Comunidades Autónomas, si su futuro Estatuto de Autonomía lo preveía, les corresponderia: "museos, bibliotecas y conservatorios de música de interés para la Comunidad Autónoma" (artículo 148.1.15), "Patrimonio monumental de interés de la Comunidad Autónoma" (articulo 148.1.16), y "El fomento de la cultura..." (artículo 148.1.17).

Además de esta distribución de competencias, el artículo 149.2 establecia: "Sin perjuicio de las competencias que podrán asumir las Comunidades Autónomas, el Estado considerará el servicio de la cultura como deber y atribución esencial y facilitará la se reflejaba en Legislación sobre esta materia emanada del poder legislativo autonómico, como era el caso del País Vasco.

La doctrina de la Sentencia 17/1991 permitió a las Comunidades Autónomas que carecian de un texto propio de rango legal valorar las oportunidades que el ordenamiento jurídico ofrecia para dotarse de una normativa autonómica que sirviera, por una parte, para adecuar el régimen jurídico del Patrimonio cultural a la normativa y peculiaridades administrativas de cada Comunidad o a distintos cambios legislativos producidos después de la entrada en vigor de la Ley 16/1985 y, por otra parte, para acomodar la función social de la propiedad de los bienes culturales a la realidad y politicas de cada territorio.

El ordenamiento jurídico español presenta actualmente la existencia de catorce Leyes generales sobre Patrimonio Histórico y Cultural procedentes de Comunidades Autónomas que se unen a la Ley estatal 16/1985 asi como a otros textos con rango de Ley que, también desde las Comunidades Autónomas, se dedican a la regulación de servicios y sectores específicos de dicho Patrimonio, como es el caso de los Archivos, Bibliotecas y Museos. Este panorama normativo es frecuentemente criticado por la doctrina, que lamenta la vuelta a un estado de dispersión cuya superación aparece como uno de los objetivos perseguidos por la Ley de 1985.

En un momento como el actual, en el que la legislación general sobre Patrimonio emanada de las Comunidades Autónomas es todavía reciente y apenas se cuenta con datos estadísticos o resoluciones judiciales sobre la aplicación de esta nueva normativa, resulta aún dificil hacer una valoración de los avances que su existencia ha supuesto para el cumplimiento de los principios rectores de la actuación de los poderes públicos sobre el Patrimonio histórico y cultural (establecidos en los artículos 44 y 46 de la Constitución de 1978) que constituyen, en definitiva, el fin último de la legislación sobre esta materia. En cualquier caso, lo que sí es posible apreciar es que la existencia de una normativa propia 


\section{$038-039$ \\ Debate e Investigación}

La acomodación del PH al Estado Autonómico.

Regulación normativa, etc.

\section{PH48 - Abril 2004}

comunicación cultural entre las Comunidades Autónomas, de acuerdo con ellas".

Es difícil compendiar en unas pocas líneas el contenido y el alcance de todos estos preceptos constitucionales. Haciendo un esfuerzo sintetizador se pueden adelantar las siguientes ideas:

$>$ Al Estado le corresponde, como competencia básica e intransferible, la lucha contra la expoliación y la exportación ilegal. Esta atribución comporta, por un lado, el mandato primario de definir conceptualmente en qué consiste la expoliación y cuáles son los supuestos en que la exportación de bienes culturales puede ser ilícita. Y a partir de estas definiciones hay que establecer los procedimientos, los instrumentos y los órganos específicos para luchar contra ambas actividades.

$>$ Corresponde también al Estado la competencia sobre los Museos, las Bibliotecas y los Archivos de titularidad estatal, sin perjuicio de su gestión por parte de las Comunidades Autónomas. Esta atribución comporta varias consecuencias: dar un concepto jurídico de Museo, de Biblioteca y de Archivo (o confirmar la validez de esas nociones en el ordenamiento preconstitucional), establecer criterios para conocer cuáles de estos centros son de titularidad estatal, fijar su régimen jurídico y determinar en qué supuestos y bajo qué régimen se puede transferir la gestión de estos centros a las Comunidades Autónomas.

$>$ Aun sin conexión directa con el contenido del referido artículo 149.1.28, pero sí relacionado con otros muchos puntos del mismo artículo 149.1 (relaciones internacionales, legislación mercantil, penal y civil, propiedad intelectual, régimen aduanero y arancelario, comercio exterior, Hacienda general y régimen jurídico de las Administraciones Públicas), le queda al Estado una competencia normativa sobre muchas actividades conectadas, de cerca o de lejos con los bienes culturales, actividades que vie- nen a constituir el segundo núcleo que rodea al estatuto jurídico de tales bienes (propiedad, comercio, comercio exterior, ejecución de Tratados internacionales, tributos, delitos y faltas, etc.).

$>$ En ejecución del artículo 149.2, el Estado debe asegurar la comunicación cultural entre las Comunidades de acuerdo con éstas. Esto comporta, por un lado, apurar la utilización de los instrumentos de cooperación previstos en el ordenamiento (los que se establecen en la Ley 30/1992, de 26 de noviembre, de Régimen Jurídico de las Administraciones Públicas y del Procedimiento Administrativo Común, profundamente modificada, en esta materia, por la Ley 4/1999, de 13 de enero) y, por otro, tomar la iniciativa en las políticas concretas a condición, claro, de que se avance por el sendero de la cooperación.

Como puede observarse, y a modo de resumen, de la combinación de las diversas previsiones establecidas en los artículos 148 y 149 de la Constitución en punto a Patrimonio Histórico se desprende que el texto constitucional vino a establecer un modelo de gestión ampliamente descentralizado, modelo fundado en atribuir competencias tasadas al Estado y relativamente amplias a las Comunidades, a condición de que sus respectivos Estatutos de Autonomía las asumieran ¿Cómo se incardinaron tales competencias en los Estatutos?

\section{La trasposición de las previsiones constitucionales a los Estatutos de Autonomía}

El primer Estatuto de Autonomía que se aprobó tras la Constitución de 1978 fue el del País Vasco de 1979 (Ley Orgánica 3/1979, de 18 de diciembre), que en materia de Patrimonio Histórico contemplaba lo siguiente:

"Artículo 10. La Comunidad Autónoma del País Vasco tiene competencia exclusiva en las siguientes materias: | ... 17. Cultura, sin perjuicio de lo dispuesto en el artículo 149.2 de la Constitución. | en las Comunidades Autónomas presenta importantes aspectos positivos para la actuación que los poderes públicos desarrollan en cumplimiento de la misión que nuestro Estado les confia en relación con el Patrimonio histórico, artístico y cultural, como a continuación tendremos ocasión de ver.

En primer lugar hay que señalar que es indudable que la acción legislativa de las Comunidades Autónomas en este campo favorece la adecuación de las normas que rigen en este sector a la realidad socioeconómica de los distintos territorios, lógicamente mejor conocida y más fácilmente abarcable desde una instancia más próxima y de ámbito territorial más restringido que la estatal.

La aprobación de las Leyes de las Comunidades Autónomas sobre esta materia ha proporcionado, por otra parte, la oportunidad de aclarar y completar la regulación de algunos aspectos de la normativa estatal que se han revelado conflictivos en su aplicación, además de permitir una actuación más ágil cuando sea preciso el desarrollo o, en su caso, la modificación de la normativa para su mejor adaptación a las circunstancias de la realidad social en que haya de aplicarse. Estas normas han permitido también la consideración de determinados sectores del patrimonio cultural de interés para las Comunidades Autónomas cuyo tratamiento general en la Ley estatal se ha querido completar o ampliar. En este sentido puede tomarse como ejemplo la especial atención que la Ley de Patrimonio Cultural de Castilla y León dispensa al Patrimonio Arqueológico, dada la especial riqueza que este sector del Patrimonio, particularmente vulnerable, presenta en un territorio que cuenta con testimonios materiales de la historia del hombre desde los origenes de nuestra especie. Análogamente puede percibirse el mismo propósito de ampliar, precisar o completar la legislación estatal en el tratamiento jurídico de sectores como el Patrimonio Etnográfico inmaterial, Industrial o el Lingüístico o en la regulación de nuevas actividades de todo tipo vinculadas a modernas tendencias en el uso del Patrimonio Cultural, como recurso de carácter turístico y recreativo o a métodos de investigación y difusión. 
18. Instituciones relacionadas con el fomento y enseñanza de las bellas artes. Artesanía.| 19. Patrimonio histórico, artístico, monumental, arqueológico y científico, asumiendo la Comunidad Autónoma el cumplimiento de las normas y obligaciones que establezca el Estado para la defensa de dicho patrimonio contra la exportación y la expoliación. | 20. Archivos, bibliotecas y museos que no sean de titularidad estatal.| 31. Ordenación del territorio y del litoral, urbanismo y vivienda...".

El último Estatuto de Autonomía que se publicó en el Boletín Oficial del Estado fue el de Castilla y León (Ley 4/1983, de 25 de febrero), que contenía los siguientes preceptos:

"Artículo 32. Competencias exclusivas. 1. La Comunidad de Castilla y León tiene competencia exclusiva en las siguientes materias: | ... $2^{a}$. Ordenación del territorio, urbanismo y vivienda. | ...11 $1^{\mathrm{a}}$. Artesanía y demás manifestaciones populares de interés de la Comunidad. | $12^{\mathrm{a}}$. Patrimonio histórico, artístico, monumental, arqueológico, arquitectónico y científico de interés para la Comunidad, sin perjuicio de la competencia del Estado para su defensa contra la exportación y la expoliación. | 13a . Museos, bibliotecas, archivos y otros centros culturales y de depósito de interés para la Comunidad y que no sean de titularidad estatal. En los mismos términos, conservatorios de música y danza, centros dramáticos y otras instituciones relacionadas con el fomento y la enseñanza de las bellas artes. | 14 $4^{\mathrm{a}}$. Fiestas y tradiciones populares. $\mid \ldots 16^{\text {a }}$. Cultura, con especial atención a las distintas modalidades culturales de la Comunidad. Las academias que tengan su sede central en Castilla y León..."'3.

"Artículo 36. Competencias de ejecución. Corresponde a la Comunidad de Castilla y León, en los términos que establezcan las leyes y las normas reglamentarias que su desarrollo dicte el Estado, la función ejecutiva en las siguientes materias: | ... 4. Gestión de museos, archivos, bibliotecas y colecciones de naturaleza análogas de titularidad estatal que no se reserve el Estado. Los términos de la gestión serán fijados mediante convenios. | ... 9. Propiedad intelectual..."

Entre el artículo 10 del Estatuto de Autonomía para el País Vasco de 1979 y los artículos 32 y 36 del Estatuto de Autonomía de Castilla y León de 1983 median tres años y medio y quince Estatutos. ¿Hubo muchas formulaciones diferentes de las que expresan el Estatuto más antiguo y el más reciente?

Es sabido que, al menos en lo que a las competencias se refiere, los diecisiete Estatutos de Autonomía (los cuatro denominados de vía rápida, aún inalterados, y los trece de vía lenta, hoy reformados varias veces) reproducen los mismos contenidos y en materia de Patrimonio Histórico se repite esa regla. De modo que el lector tiene, con los preceptos que acabamos de reproducir, una idea precisa del contenido cultural de los Estatutos. Y de este contenido se infieren algunas conclusiones:

$>$ La singularización de la competencia sobre los bienes que conforman el Patrimonio Histórico así como sobre los centros de depósito cultural se funda en la noción de interés. La jurisprudencia del Tribunal Constitucional, precisamente en una sentencia de contenido cultural que comentaremos más abajo, la 42/1981, de 22 de diciembre, ya señaló la complejidad de esta técnica de distribuir competencias por medio del concepto indeterminado de los "intereses". Frente a esta técnica, otras se basan en criterios mucho más objetivos (la tenencia o la carencia de la titularidad, por ejemplo). El resultado es que pueda dar lugar a alguna colisión aunque en la práctica éstas han sido escasas.

$>$ En sentido material, los Estatutos han sabido extraer el máximo de las posibilidades que ofrecía la Constitución, de modo que
El estatuto jurídico de la propiedad de los bienes culturales en la legislación procedente de las Comunidades Autónomas aparece claramente inspirado en la Ley estatal de 1985. Las últimas leyes aprobadas han optado, incluso, por un sistema de protección integrado por categorias uniformes respecto de las previstas en la Ley estatal. La Ley de Castilla y León se sitúa deliberadamente en esta tendencia, como queda de manifiesto en su Exposición de Motivos, en aras de la homogeneidad, coordinación y colaboración interadministrativa que el legislador considera necesarias para la protección del Patrimonio Cultural. La búsqueda de una protección más eficaz y el respeto al ámbito de competencias del Estado han llevado igualmente a remitir en ocasiones la regulación de determinados aspectos a la legislación estatal.

No obstante lo anterior, la búsqueda de un sistema de protección más eficaz y adecuado a los objetivos de las politicas de las distintas Comunidades Autónomas también ha proporcionado novedades significativas respecto de la legislación estatal. Entre ellas merecen ser destacadas algunas como la opción en la mayor parte de las Leyes autonómicas por una prohibición sólo relativa de los cambios de alineaciones en conjuntos de inmuebles, menos estricta que en la Ley de 1985 , las diferentes soluciones que se han dado al tratamiento de la declaración de ruina de edificios históricos, o el desarrollo de nuevas categorias y procedimientos para la identificación y clasificación de los bienes para la determinación del régimen jurídico aplicable. La creación de un nivel de protección intermedio para los bienes inmuebles, inexistente en la Ley estatal 16/1985 y que se ha instituido tanto en la legislación propia de nuestra Castilla y León con un régimen de tutela descentralizado en los municipios- como en las Leyes emanadas de otras Comunidades Autónomas puede ser la novedad de mayor alcance, en el sentido expuesto.

Mayor importancia presenta en las Leyes autonómicas sobre Patrimonio el refuerzo de las técnicas de ejercicio de la autoridad por parte de la Administración para controlar o imponer el cumplimiento de la normativa, mediante la actualización y habilitación de 


\section{$040-041$ \\ Debate e Investigación}

La acomodación del PH al Estado Autonómico.

Regulación normativa, etc.

\section{PH48 - Abril 2004}

han atribuido competencias sobre todo el Patrimonio Histórico, en todas sus expresiones y formas incluido incluso el etnográfico, sobre todos los centros de depósito cultural no estatales, sobre la gestión de los centros de depósito cultural estatales y, a modo de cláusula de cierre, sobre ese concepto más delicado pero más inaprensible que es la cultura.

> También en sentido material, los Estatutos han rodeado a las competencias stricto sensu sobre Patrimonio Histórico de otras atribuciones necesarias para el ejercicio de las primeras: urbanismo y propiedad intelectual, principalmente.

> Como el artículo 148.1 de la Constitución no presenta límites, el contenido de estas competencias es pleno: legislativo, reglamentario y gestión, salvo, naturalmente, cuando se trata de competencias estatales a las que concurren las Comunidades Autónomas con alguna función, como ocurre con los Archivos, Bibliotecas y Museos de titularidad estatal.

> Como consecuencia de la plenitud de competencias que suele corresponder a las Comunidades Autónomas, todos sus órganos institucionales (Asamblea Legislativa, Consejo de Gobierno, Administración ordinaria) recibieron atribuciones en materia de $\mathrm{Pa}$ trimonio Histórico, atribuciones que, en el caso del Consejo de Gobierno y de la Administración, comportaba la creación de Consejerías y unidades administrativas diversas.

La conclusión que se desprende de cómo se ha efectuado la trasposición de las previsiones constitucionales hasta los Estatutos de Autonomía es que, sin excepción, el poder estatuyente ha apurado las posibilidades constitucionales (artículo 148.1 principalmente) y hasta las ha rebasado como en el curioso caso de los Archivos que no se citan en el artículo 148.1.15 como materia asumible por las Comunidades Autónomas pero que han venido a aparecer en los Estatutos de Autonomía a través de una interpretación conjunta, quizá forzada, de lo previsto en los artí- culos 149.3, primer inciso, y 148.2. En todo caso, con la aprobación de los Estatutos las Comunidades Autónomas adquirieron amplias competencias que podian ejercitar. Lógicamente, esas competencias se podian ejercitar mejor cuando el Estado transfiriera sus servicios, por lo que el paso siguiente fue, precisamente, la complicada operación de traspaso de servicios y funciones.

\section{La ejecución del modelo descentralizador a través de las transferencias de funciones y servicios del Estado a favor de las Comunidades Autónomas}

Desde que se constituyeron las primeras Cortes democráticas en 1977 la presión regional empezó a constituir uno de los elementos más característicos de la transición pues el antecedente de los Estatutos republicanos de autonomía en Cataluña y en el País Vasco, más la propia existencia de partidos nacionalistas con relevante representación parlamentaria pusieron ante el Gobierno del Presidente Suárez un reto de inmediata resolución. Como consecuencia de la negociación directa del señor Suárez con el Presidente de la Generalidad de Cataluña en el exilio, Tarradellas, se inició la fórmula de los regímenes provisionales de autonomía que aprobaba el Gobierno por Decreto-Ley, que se extendió por casi todo el territorio nacional si bien algunas pocas provincias no llegaron a acceder a ese tipo de organización.

Luego, antes de constituirse las Comunidades Autónomas, los Entes Preautonómicos empezaron a recibir competencias, funciones y servicios del Estado. En materia de Patrimonio Histórico o materias conexas como el urbanismo, los Entes preautonómicos que recibieron competencias fueron: País Vasco (Real Decreto 1981/1978, de 15 de julio: urbanismo), Galicia (Real Decreto 212/1979, de 26 de enero: urbanismo; y Real Decreto 1634/1980, de 31 de julio: Centro Nacional de Lectura y Tesoro Bibliográfico), Aragón (Real Decreto 298/1979, de 26 de enero: urbanismo; y Real Decreto 3529/1981, nuevos instrumentos como por ejemplo: multas coercitivas; ampliación de los supuestos de expropiación por incumplimiento de la función social de la propiedad; regulación y cualificación de la actividad inspectora; régimen de infracciones y sanciones, etc.

En la aplicación de la normativa, las Leyes procedentes de las Comunidades Autónomas ofrecen además una tendencia a garantizar la objetividad en el ejercicio de las funciones de control y autorización previa de intervenciones reduciendo el ámbito de la discrecionalidad de la Administración, en unos casos mediante una mayor precisión en la propia Ley de los criterios generales que han de regir éstas, y en otros previendo su concreción en los actos administrativos de ordenación o clasificación de los bienes culturales. Esta tendencia, dirigida a la creación de un marco de mayor certeza jurídica en torno al régimen de los distintos bienes culturales, puede ser altamente positiva en la medida en que favorece la confianza necesaria para el uso social del Patrimonio cultural, superando la pérdida de funcionalidad que en muchos casos constituye la raíz de su deterioro.
En el examen de estas normas también encontraremos intensificada la relación con otras áreas de la actuación administrativa de competencia de las Comunidades Autónomas, tanto en los aspectos referentes a la normativa sectorial de otros campos de la actividad de policía administrativa (Medio Ambiente; Ordenación del Territorio; Urbanismo: ruina, planeamiento, articulación de los informes y trámites de la Administración competente en materia de cultura en los procedimientos de concesión de licencias, autorizaciones y órdenes urbanisticas de ejecución), como en la habilitación y empleo de instrumentos propios de otras formas de actuación de la Administración: previsión de servicios públicos, normas especiales sobre organización y empleo público, normas sobre gestión presupuestaria.

La normativa autonómica ha mantenido la importancia de las medidas de fomento como elemento consustancial al estatuto de la propiedad de los bienes culturales. El carácter esencialmente voluntario de estas técnicas ha actuado en beneficio de sus destina- 
de 29 de diciembre: Centro Nacional de Lectura y Tesoro Bibliográfico), Comunidad Valenciana (Real Decreto 299/1979, de 26 de enero: urbanismo; y Real Decreto 278/1980, de 25 de enero: Centro Nacional de Lectura y Tesoro Bibliográfico), Andalucia (Real Decreto 698/1979, de 13 de febrero: urbanismo), Cataluña (Real Decreto 2210/1979, de 7 de septiembre: Centro Nacional de Lectura, Bibliotecas, Tesoro Bibliográfico incluyendo la exportación de los bienes constitutivos del Tesoro Bibliográfico), Islas Baleares (Real Decreto 2245/1979, de 7 de septiembre: urbanismo; Real Decreto 2873/1979, de 17 de septiembre: Museo Saridakis; y Real Decreto 2567/1980, de 7 de noviembre: Centro Nacional de Lectura, Bibliotecas, Tesoro Bibliográfico), Canarias (Real Decreto 2843/1979, de 7 de diciembre: urbanismo y Centro Nacional de Lectura y Tesoro Bibliográfico), Asturias (Real Decreto 2874/1979, de 17 de diciembre: urbanismo y Centro Nacional de Lectura y Tesoro Bibliográfico), Extremadura (Real Decreto 2912/1979, de 21 de diciembre: urbanismo y Centro Nacional de Lectura y Tesoro Bibliográfico), Castilla - La Mancha (Real Decreto 3072/1979, de 29 de diciembre: Centro Nacional de Lectura y Tesoro Bibliográfico); Región de Murcia (Real Decreto 466/1980, de 29 de febrero: Centro Nacional de Lectura y Tesoro Bibliográfico); y Castilla y León (Real Decreto 3528/1981, de 29 de diciembre: Centro Nacional de Lectura y Tesoro Bibliográfico).

De modo que antes de crearse las Comunidades Autónomas once Entes Preautonómicos empezaron a gestionar sus bienes culturales a través del urbanismo y del Patrimonio Bibliográfico más un Museo en el caso de las Islas Baleares. Este primer bloque de transferencias fue muy significativo pues incorporó la gestión urbanística, lo que comportaba un primer control autonómico sobre las Entidades Locales y porque, además, pretendió actuar a modo de ensayo al transferir toda la gestión del Patrimonio bibliográfico. Pero lógicamente estos tanteos sólo podrían confirmarse a partir de la creación de las Comunidades Autónomas.
Constituidas las Comunidades Autónomas, empezó un proceso, largo y complejo, para traspasar las competencias, los servicios y los medios, proceso que duró unos siete años. El primer Decreto específico de traspaso en materia de Patrimonio Histórico a favor de una Comunidad Autónoma ya creada fue el Real Decreto 1676/1980, de 31 de julio, de traspaso a la Comunidad Autónoma de Cataluña de la gestión de las Bibliotecas de titularidad estatal, y no deja de ser significativo que lo primero que se traspasara fuera, no una competencia autonómica, sino una competencia estatal. Después de esa única transferencia parcial, los sucesivos Decretos de traspasos abarcaban todo el campo del Patrimonio Histórico (el primero fue el Real Decreto 3069/1980, de 26 de septiembre, para el País Vasco) siendo muy rotunda la fórmula del traspaso:

"La Comunidad Autónoma asume el ejercicio de las competencias, facultades y potestades que hasta ahora ostentaba la Administración del Estado en materia de defensa y protección del Patrimonio Histórico-Artístico, Arqueológico y Monumental en el territorio de la Comunidad Autónoma", añadiendo a continuación algunas previsiones sobre la licencia de exportación, la comunicación de transmisiones inter vivos, la comunicación recíproca de ambas Administraciones, y el ejercicio de expropiación forzosa y del derecho de preferente adquisición (punto 10 del Anexo del Real Decreto 3069/1980, de 26 de septiembre, citado).

A comienzos de 1987 se pudo dar por terminado este proceso de traspasos que provocó la remisión de toda la documentación, la transferencia del personal, la cesión de la titularidad de muchos bienes y, aunque no era constitucionalmente obligado, el desplazamiento de la gestión de los Archivos, Bibliotecas y Museos de titularidad estatal ${ }^{5}$. Hay que señalar, en fin, que todo este proceso de transferencias fue el que probó en la práctica (podriamos decir que visualizó) que el Patrimonio Histórico ya era realmente una compe- tarios, pues ha dado lugar a la articulación de nuevos instrumentos de fomento y de intervención técnica y financiera desde todas las Administraciones públicas territoriales que ejercen competencias sobre el Patrimonio histórico y cultural, enriqueciendo la oferta de aquéllos con nuevas modalidades de ayuda, estimulo o compensación a las cargas inherentes a la conservación y vinculación de los bienes históricos al disfrute público, de naturaleza diversa: ayudas económicas fiscales o no, asistencia técnica, honorificas, etc. La habitual previsión en Leyes autonómicas, como la vigente en nuestra Comunidad, de una reserva mínima de carácter fijo en los presupuestos de las obras públicas, análoga a la establecida en la Ley de Patrimonio Histórico Español y destinada a la protección y tutela del patrimonio cultural, es claro exponente del grado de compromiso que los poderes públicos de las Comunidades Autónomas han querido asumir.

La legislación y actuación administrativa derivadas del ejercicio de las competencias estatales, por otra parte, han venido reconociendo la existencia de las nuevas leyes autonómicas, a las que se ha conferido virtualidad a efectos como la protección penal, la defensa contra la exportación ilícita o el reconocimiento de beneficios fiscales.

El examen de la normativa emanada de las Comunidades Autónomas, en la medida en que pone de manifiesto como líneas directrices, por una parte, la voluntad de ofrecer instrumentos para una protección más completa y eficaz del Patrimonio histórico y cultural y, por otra, el compromiso de la sociedad en relación con los bienes en los que se materializa su herencia cultural, ofrece así un positivo marco de corresponsabilidad entre ciudadanos y poderes públicos que ha de tenerse en cuenta a la hora de valorar, desde un punto de vista formal, los avances experimentados por la aprobación de las normativas autonómicas. La actividad y medios que se dispongan para hacer efectivas las previsiones de este marco jurídico y la coordinación entre las diversas instancias que actúan sobre el Patrimonio permitirán valorar en el futuro el alcance real de sus previsiones. 


\section{$042-043$ \\ Debate \\ e Investigación}

La acomodación del PH

al Estado Autonómico.

Regulación normativa, etc.

\section{PH48 - Abril 2004}

tencia autonómica. Hay que recordar siempre que son los Estatutos de Autonomía los que atribuyen la titularidad de una competencia pero el ejercicio de esta competencia resulta siempre problemático si no se produce el traspaso de los servicios y medios del Estado.

\section{Adecuación de la Administración periférica del Estado, en} el ramo de Cultura, a la nueva descentralización

A partir de la transferencia de servicios y medios a las Comunidades Autónomas, la persistencia de la Administración periférica del Estado no estaba justificada para la mayoría de los Departamentos ministeriales como se ordenó, con carácter general, en el Real Decreto 1223/1983, de 4 de mayo. En ejecución de esta norma se dictó el Real Decreto 1686/1984, de 4 de julio, por el que se suprimieron las Direcciones Provinciales del Ministerio de Cultura en las Comunidades Autónomas donde persistía esta estructura administrativa ${ }^{6}$.

Al mismo tiempo, el Estado trató de aplicar en Cataluña una práctica más descentralizada, de modo que el Real Decreto 1712/1984, de 1 de agosto, creó la Comisión Delegada en Cataluña de la Junta de Calificación, Valoración y Exportación de Obras de Importancia Histórica o Artística. La experiencia no fue positiva por lo que varios años después, mediante el Real Decreto $1031 / 1987$, de 26 de junio, se suprimió esta Comisión Delegada y la cooperación que presuponía pasó a ejercitarse a través de cuatro representantes de Cataluña en la mencionada Junta, que había pasado a denominarse Junta de Calificación, Valoración y Exportación de Bienes del Patrimonio Histórico Español.

\section{Creación de los servicios autonómicos de gestión cultural}

En el ejercicio de su competencia de autoorganización, las Comunidades Autónomas organizaron, normalmente desde el régimen preautonómico, los servicios encargados de las políticas públicas de cultura. La normativa, usualmente de rango reglamentario, que se ha producido es ingente y difícil de seleccionar. Es más útil explicar brevemente el modelo aplicado, que suele ser el mismo con pocas variantes. En realidad, como también ocurre en el resto de los ramos administrativos, la gestión de la cultura en general y del Patrimonio Histórico, en particular, responde en las Comunidades Autónomas a un modelo muy parecido al de la Administración General del Estado: Ministerio/Consejeria>Dirección General>Subdirección General o Servicio.

Más en concreto, el modelo organizativo se levanta sobre una Consejería que puede dedicarse sólo al ramo de la cultura o, con mucha frecuencia, comparte la gestión de la cultura con otras materias como puede ser la educación, el medio ambiente o el turismo. La gestión específica del Patrimonio Histórico corre a cargo habitualmente de una Dirección General de Bellas Artes, o de Bienes Culturales, si bien en las Comunidades Autónomas más extensas puede haber incluso una segunda Dirección General. La o las Direcciones Generales se componen de un mínimo de dos o tres Subdirecciones o Servicios (según la denominación de cada Administración autonómica) dedicadas, como poco, a los Museos, a las Bibliotecas y Archivos, a las excavaciones arqueológicas, a la promoción y difusión y, también, a la tramitación de las diversas categorias de declaraciones con la consiguiente llevanza de registros e inventarios. En casi todas las Comunidades Autónomas pluriprovinciales se ha establecido, además, una estructura periférica y, con menos intensidad en este período, se crearon órganos asesores, frecuentemente semihonoríficos.

Esta organización se fundaba en la competencia de autoorganización, a partir de los Decretos de organización de los Consejos de Gobierno y de organización administrativa de las Consejerías o Departamentos. Posteriormente, cuando se aprobaron las Leyes del Patrimonio Cultural, algunos de estos órganos quedaron legalizados.

\section{Primeras normas autonómicas}

Si el Estado no llegó a elaborar una Ley general (aunque lo intentó, como veremos), menos aún lo iban a intentar las Comunidades Autonómicas. Sin embargo, no faltaron relevantes normas autonómicas que obedecian a dos designios. En unos casos, desarrollar la antigua legislación estatal para mejor aplicación de las competencias recién recibidas: ese fue el caso del Decreto catalán 180/1982, de 11 de mayo, que regula el procedimiento para la declaración de monumentos y conjuntos histórico-artísticos o el del Decreto vasco 52/1984, de 13 de febrero, para el mismo objetivo o el Decreto balear 29/1983, de 15 de diciembre, de similar contenido, o también el Decreto Foral navarro 48/1983, de 15 de diciembre, sobre aprobación de los proyectos de obras en monumentos y conjuntos histórico-artísticos.

El otro fin de las nuevas normas autonómicas fue, sin conectar directamente con la antigua legislación estatal, regular con vocación general una rama completa del Patrimonio Histórico de las que conformaban su competencia o algún tipo específico de acción protectora. Asi se aprobaron, en materia de Archivos, la Ley andaluza Andalucía 3/1984, de 9 de enero, y la Ley catalana 6/1985, de 26 de abril. Para las Bibliotecas se promulgaron la Ley catalana 3/1981, de 22 de abril, así como la Ley andaluza 8/1983, de 3 de noviembre. Y en lo que se refiere a los Museos el Parlamento de Andalucía aprobó la Ley 2/1984, de 12 de julio. Además, en lo que al fomento se refiere, el Parlamento de Galicia aprobó la Ley de 11 de diciembre de 1984, relativa a los trabajos de dotación artística en edificios y construcciones públicas.

En esa misma dirección iría la profusa normativa reglamentaria que aprobaron muchas Comunidades Autónomas que no pretendía dictarse en desarrollo de la Ley de Excavaciones Arqueológicas de 1911 y que solía dictarse invocando, únicamente, las competencias estatutarias o las funciones transferidas. Bajo esta fórmula se dictaron, durante este periodo, Decretos u Órdenes en Cataluña, Galicia, Andalucía, Cantabria, la Región de Murcia, Aragón, y Castilla y León.

En definitiva, las Comunidades Autónomas fueron muy pronto conscientes del alcance jurídico de la atribución de la competencia exclu- 
siva en estas materias y, en consecuencia, prepararon rápidamente normas que permitieran el mejor ejercicio de sus atribuciones.

En este período no le faltaron al Tribunal Constitucional ocasiones para pronunciarse sobre el alcance jurídico de las competencias relativas al Patrimonio Histórico. Citamos la sentencia 42/1981, de 22 de diciembre, la sentencia 84/1983, de 24 de octubre, y la sentencia 149/1985, de 5 de noviembre, ampliamente comentadas por Ruiz-Rico en su artículo "El derecho andaluz del patrimonio histórico desde una perspectiva constitucional", y al cual remitimos.

\section{Trabajos de carácter doctrinal}

En un período tan volcado a elaborar los fundamentos dogmáticos del nuevo ordenamiento, la doctrina se ocupó poco de esta secundaria materia del régimen jurídico del Patrimonio Histórico. El primer trabajo, en lo que yo tengo registrado, si no sobre esta materia al menos sobre la cultura, fue el de Francisco Serra Pagán Cultura española y autonomías (Servicio de Publicaciones del Ministerio de Cultura, Madrid, 1980) que era un muy digno trabajo sobre la regulación de la cultura en el constitucionalismo comparado, en la Constitución española, en los proyectos de Estatutos de Autonomía existentes en aquel momento y en la legislación local. Era un trabajo descriptivo y bien informado y por ello resultó útil.

Dos años después el profesor Santiago Muñoz Machado elaboró dos grandes trabajos que aportaron rigor a una materia todavía confusa. Por un lado elaboró un gran informe, de escasa difusión al no tener carácter venal, titulado La distribución de competencias entre el Estado y las Comunidades Autónomas en materia de cultura (Secretaría General Técnica del Ministerio de Cultura, Madrid, 1982) donde efectuaba, en primer lugar, una correcta propuesta de distribución de competencias entre el Estado y las Comunidades Autónomas sobre la base de la concurrencia total ex artículo 149.2. En segundo lugar, repasaba todas las competencias culturales por lo que se aportaban algunas consideraciones sobre los Museos, las Bibliotecas y los Archivos y el Patrimonio Histórico-artístico. En tercer lugar, por último, aportaba diversas fórmulas de cooperación. El trabajo de Muñoz Machado fue en cierto modo resumido en el Capítulo XI, "Cultura", en su Derecho público de las Comunidades Autónomas (Eds. Civitas, Madrid, 1982, t. I, págs. 574-600). El doble texto de Muñoz Machado fue, hasta la aprobación de la Ley en 1985, el trabajo más profundo y minucioso dedicado al régimen jurídico del Patrimonio Histórico.

En definitiva, salvo la meritoria aportación de Serra Pagán y la elaboración cuidada de Muñoz Machado, la doctrina apenas quiso entrar en un tema que se veía muy lejano para la mayoría de los juristas.

Si quisiéramos aportar unas conclusiones sobre este período 1978-1985 podríamos avanzar dos notas básicas: su excepcionalidad y su riqueza normativa. Por una parte, fue un período ex- cepcional aquel en que se establece el Estado democrático descentralizado por medio de la Constitución de 1978. Igualmente excepcional es la creación de diecisiete Comunidades Autónomas por medio de la aprobación de sus Estatutos de Autonomía. Pero al tiempo que excepcional fue un período muy rico pues dio lugar a una reestructuración administrativa extensa, a la aprobación de importantes Leyes autonómicas sectoriales y a los primeros pasos en el desarrollo autonómico de la legislación estatal. En cambio, la doctrina fue escasa aunque rica y la jurisprudencia constitucional no tuvo ocasión de avanzar más allá de la genérica noción de cultura. En realidad, el tiempo estaba maduro para que el Estado aprobara una Ley general que desarrollara sus competencias y creara el marco jurídico-conceptual adecuado. Y de hecho, el Gobierno de la Unión del Centro Democrático, presidido ya por el señor Calvo-Sotelo, aprobó el Proyecto de ley por el que se regula con carácter general la defensa del Patrimonio Histórico-Artístico (Boletín Oficial de las Cortes Generales. Congreso de los Diputados, I Legislatura, Serie A, núm. 207-I, 14 de septiembre de 1981) que no se pudo aprobar a causa de la disolución de las Cortes Generales en septiembre de 1981.

\section{El período 1985-1991}

A mediados de 1985 se publicó la Ley 16/1985, de 25 de junio, del Patrimonio Histórico Español. Sin querer hacer juegos de palabras se puede decir que fue un día histórico porque tanto la historia jurídica del Patrimonio Histórico en España como la historia de la distribución competencial Estado/Comunidades Autónomas en esta materia tienen como fecha central el de la promulgación de la Ley. Por ende, este período está impregnado del fortísimo peso de la Ley $16 / 1985$, de 25 de junio. Y ese es el primer punto que vamos a ver, esto es, el contenido competencial de la Ley y las normas reglamentarias que la desarrollaron.

Al aprobarse la ley estatal se abrió la posibilidad de que las Comunidades Autónomas "se atrevieran" a preparar sus propias Leyes generales. Muy pocas Comunidades Ilegaron a hacerlo antes de que terminara este período que concluye el día 31 de enero de 1991 cuando el Tribunal Constitucional dictó su sentencia sobre la Ley 16/1985, de 25 de junio. Pero si sólo dos Comunidades Autónomas (Castilla-La Mancha y el País Vasco) aprobaron Leyes generales, otras muchas Comunidades aprobaron Leyes sectoriales muy relevantes. Esas leyes, generales y sectoriales, serán el contenido del segundo punto de este periodo.

En tercer lugar habria que estudiar si hubo alguna jurisprudencia constitucional que avanzara en el inexplorado campo del Patrimonio Histórico y, en cuarto y último lugar, veremos si se enriqueció la escasa respuesta doctrinal.

Por el contrario, no nos detendremos en la organización política y administrativa de la gestión de los bienes culturales pues en conjunto no ha sufrido cambios importantes respecto al período anterior. 


\section{$044-045$ \\ Debate \\ e Investigación}

La acomodación del PH

al Estado Autonómico.

Regulación normativa, etc.

PH48 - Abril 2004

Contenido autonómico de la Ley 16/1985, de 25 de junio, del Patrimonio Histórico Español

Puede parecer paradójico hablar del contenido autonómico de una Ley estatal, y no autonómica, pero lo cierto es que la Ley 16/1985, de 25 de junio, del Patrimonio Histórico Español, responde perfectamente a la categoria de Leyes a que se refiere el artículo 28.1 de la Ley Orgánica 2/1979, de octubre, del Tribunal Constitucional: "las Leyes que, dentro del marco constitucional, se hubieran dictado para delimitar las competencias del Estado y las diferentes Comunidades Autónomas...". Asi es la Ley 16/1985, de 25 de junio, pues es la norma legislativa que permite corporizar, hacer visibles y específicas, las competencias aludidas en los artículos 149.1 y 148.1 de la Constitución y en los Estatutos de Autonomía, salvo en los casos más singulares de algunos Patrimonios especiales que las Comunidades Autónomas pudieran desarrollar previamente.

Pero ¿cuál es el contenido autonómico de la Ley 16/1985, de 25 de junio? Haciendo un resumen que siempre resultará esquemático, podemos decir que este contenido autonómico se expresa de la siguiente manera:

$>$ Un concepto definido de lo que es el Patrimonio Histórico, del que las Comunidades Autónomas no se pueden separar aunque si enriquecer y complementar.

$>$ Las funciones de la Administración General del Estado, lo que significa a contrario sensu que el resto de funciones puede corresponder a las Administraciones autonómicas.

$>$ Creación del Consejo del Patrimonio Histórico como foro de comunicación cultural Estado/Comunidades Autónomas.

$>$ Un concepto jurídico de "expoliación" como competencia estatal, luego no autonómica.

> La noción jurídica de "exportación" que al ser competencia estatal recubre actividades no autonómicas.

$>$ La figura y el procedimiento de declaración de "Bienes de Interés Cultural", lo que, incluso antes de la sentencia constitucional 17/1991, de 31 de enero, era competencia parcialmente autonómica.

$>$ El Inventario General de Bienes Muebles, de contenido parcialmente autonómico.

$>$ Los procedimientos para la protección de los bienes que constituyen el Patrimonio Histórico Español, procedimientos que debe aplicar la "Administración competente", que normalmente será la autonómica.

$>$ La noción jurídica de diversos Patrimonios especiales (arqueológico, etnográfico, documental y bibliográfico) a partir de la cual las Comunidades Autónomas pueden profundizar y ampliar.

$>$ El concepto jurídico y material de Archivo, de Biblioteca y de Museo que permite a las Comunidades regular sus propios centros. $>$ La creación de los Sistemas Españoles de Archivos, de Bibliotecas y de Museos, que permiten profundizar en la cooperación cultural.

En definitiva, sin la Ley 16/1985, de 25 de junio, del Patrimonio Histórico Español, la labor normadora de las Comunidades Autonómicas se realizaría con el mismo alcance pero con más insegu- ridad y, probablemente, con más descoordinación. Además, no debemos olvidar que la elaboración o no de una Ley general del Patrimonio Histórico es una decisión libre de cada Comunidad Autonómica. Si las Comunidades Autónomas no desean aprobar ese tipo de Leyes (como ocurre en La Rioja, en la Región de Murcia y en la Comunidad Foral de Navarra), esas Administraciones pueden aplicar la Ley estatal como hubieran aplicado la legislación preconstitucional si no existiera la Ley de 1985

Menor contenido autonómico tienen los tres Reglamentos que desarrollan la Ley ${ }^{10}$ pero el primero de éstos por orden cronológico, el Real Decreto 111/1986, de 10 de enero, de desarrollo parcial de la Ley 16/1985, de 25 de junio, del Patrimonio Histórico Español, desarrolla procedimentalmente las previsiones de la Ley en punto a declaración de Bienes de Interés Cultural y a inscripción en el Inventario General de Bienes Muebles así como regula el Consejo del Patrimonio Histórico. En cuanto a los otros dos Reales Decretos, el 620/1987, de 10 de abril, y el 582/1989, de 19 de mayo, crean los respectivos Sistemas Españoles de Museos y de Bibliotecas.

\section{Leyes autonómicas generales y sectoriales}

Como hemos visto más arriba, sólo dos Comunidades Autónomas se decidieron a aprobar Leyes generales de protección del Patrimonio Histórico: Castilla-La Mancha (Ley 4/1990, de 39 de mayo) y el País Vasco (Ley 7/1990, de 3 de julio). Ambas Leyes eran muy diferentes: la castellano-manchega nació con vocación de desarrollo de la Ley estatal en tanto que la vasca se aprobó con voluntad de apurar la competencia autonómica. Pero fueron el primer paso legislativo general que dieron las Comunidades Autónomas y así se debe señalar.

En cambio, muchas Comunidades Autónomas vieron que un camino más seguro de ordenar jurídicamente sus competencias en este campo era el de la aprobación de Leyes sectoriales, siguiendo el ejemplo andaluz y catalán. Y así se aprobaron las siguientes normas: Ley aragonesa 6/1986, de 28 de noviembre, de Archivos; Ley aragonesa 7/1986, de 28 de diciembre, de Museos; Ley aragonesa 8/1986, de 19 de diciembre, de Bibliotecas; Ley valenciana 10/1986, de 30 de diciembre, de Organización Bibliotecaria; Ley castellano-manchega 1/1989, de 4 de mayo, de Bibliotecas; Ley madrileña 10/1989, de 5 de octubre, de Bibliotecas; Ley gallega 14/1989, de 11 de octubre, de Bibliotecas; Ley castellano-leonesa 9/1989, de 30 de noviembre, de Bibliotecas; Ley canaria 3/1990, de 22 de febrero, de Patrimonio Documental y Archivos; Ley murciana 4/1990, de 11 de abril, de medidas de fomento del patrimonio Histórico; Ley murciana 5/1990, de 11 de abril, de Museos (hoy derogada); Ley murciana 6/1990, de 11 de abril, de Archivos y Patrimonio Documental; Ley murciana 7/1990, de 11 de abril, de Bibliotecas y Patrimonio Bibliográfico; Ley riojana 4/1990, de 29 de junio, de Bibliotecas; y Ley catalana 17/1990, de 2 de noviembre, de Museos.

Esta relación denota un cambio muy profundo en el ordenamiento del Patrimonio Histórico pues las Comunidades Autónomas vieron en el campo del Patrimonio Documental y Bibliográfico y en el de 
los Archivos, las Bibliotecas y los Museos el ámbito que mejor expresaba sus concepciones culturales.

En conclusión, el período legislativo que se inicia con la aprobación de la Ley estatal marca el cambio definitivo del Derecho español de los bienes culturales, si bien este cambio sólo se consolidará en el período siguiente.

A lo largo de este periodo el Tribunal tuvo ocasión de pronunciarse una vez sobre cuestiones medulares de la distribución de competencias. La sentencia 103/1988, de 8 de junio ${ }^{11}$, resolvió el recurso de inconstitucionalidad interpuesto por el Presidente del Gobierno frente a algunos artículos de la Ley andaluza 3/1984, de 9 de enero, de Archivos. La sentencia, como explica Ruiz Rico, desestimó el recurso por considerar constitucionales todos los preceptos impugnados.

Además de esta sentencia, el Tribunal Constitucional volvió sobre el tema de la cultura en dos sentencias, la 106/1987, de 25 de junio ${ }^{12}$, y la $153 / 1989$, de 5 de octubre ${ }^{13}$, por la que se resolvieron nuevos conflictos de competencia suscitado por el Consejo Ejecutivo de la Generalidad de Cataluña en relación a normas sobre producción cinematográfica, pero no tocaron, o lo bordearon, el tema de la cultura.

\section{La doctrina post-Ley}

Cada vez que se aprueba una Ley relevante para un sector de la actividad social, los juristas acostumbramos a efectuar comentarios, exégesis y monografías diversas. No pasó así con la Ley 16/1985, de 25 de junio, del Patrimonio Histórico Español a la que doctrina tardó algún tiempo en prestar atención. La primera monografía que se publicó sobre la nueva Ley fue la de Piedad García-Escudero y Benigno Pendás El nuevo régimen jurídico del Patrimonio Histórico Español (Ministerio de Cultura, Madrid, 1986), que dedicaba unas páginas de sintesis que insertaban a la nueva Ley en el complejo competencial autonómico.

Muy rigurosa fue también la monografía de la profesora Concepción Barrero Rodríguez La ordenación jurídica del Patrimonio Histórico (Instituto García Oviedo-Ed. Civitas, Madrid, 1990), que inició la serie de tesis doctorales que tanto han contribuido a consolidar esta rama del ordenamiento. En unas pocas páginas (págs. 400-411), la profesora Barrero Rodriguez vino a exponer con claridad el cuadro general de competencias.

Finalmente, y con alcance muy sintético, se encuentran algunas consideraciones sobre la distribución competencial en dos trabajos de Javier García Fernández ("La nueva legislación española sobre Patrimonio Arqueológico", Revista de Derecho Público. núm. 107, abriljunio 1987, págs. 365-399; y "Presupuestos jurídico-constitucionales de la legislación sobre Patrimonio Histórico", Revista de Derecho Político. núm. 27-28, 1988, págs. 181-212).

No fue una cosecha generosa pero el trabajo de García-Escudero y Pendás, por dar una acabada visión de la nueva Ley, y el de Ba- rrero Rodríguez, por su acertada y sintética descripción, abrieron un camino que luego ha dado sus frutos.

A modo de conclusión de este período podríamos señalar que el momento de aplicación de la Ley con una tímida continuación en dos Comunidades Autónomas, que fue también el momento de la plena asunción legislativa de los Patrimonios especiales por las Comunidades Autónomas y que, al tiempo, fue el período en que el Tribunal Constitucional se enfrentó por primera vez, no al tema de la cultura, sino al más concreto del Patrimonio Histórico. Y para acabar de caracterizar esta fase, es la que produce las dos primeras grandes monografías sobre el nuevo Derecho. No fue poco.

\section{El período 1991-2004}

La periodización histórica puede ser fuente de arbitrariedades e incorrecciones. ¿Por qué este período? El principio es obvio: el 31 de enero de 1991 el Tribunal Constitucional dictó su sentencia 17/1991 que aportó una interpretación determinada de la Ley 16/1985, de 25 de junio. ¿Y por qué 2004? Aquí hay que precisar un poco más. Primero, porque es la fecha en estamos ahora pero eso no sería suficiente si pudiéramos señalar una cesura anterior, si hubiera un hito que sirviera para separar dos etapas. Pero entre 1991 y 2004 es difícil señalar un acontecimiento, una decisión política, una norma que sirva para dar por concluido un período y comenzar otro. Tanto en lo normativo como en el silencio del Tribunal Constitucional y la eclosión doctrinal se advierte cierta continuación que no permite introducir cesuras. Por las mismas razones que señalábamos en el período anterior, no podemos detenernos en los elementos que muestran continuidad (organización administrativa, legislación estatal).

\section{La sentencia 17/1991, de 31 de enero, del Tribunal Constitucional}

Sin respetar la sistemática que hemos establecido para los períodos anteriores, hemos de iniciar éste con la sentencia 17/1991 ${ }^{14}$, de 31 de enero, pues no sólo es la causa de esta periodización sino que, además, tiene un contenido netamente legislativo.

La sentencia resolvió los recursos de inconstitucionalidad interpuestos contra varios artículos de la Ley 16/1985, de 25 de junio, por parte de los Consejos de Gobierno de las Comunidades Autónomas del País Vasco, Cataluña y Galicia así como por el Parlamento de Cataluña. El Tribunal Constitucional no declaró inconstitucional ningún artículo o apartado de la Ley pero aplicó la técnica del fallo interpretativo a varios preceptos (artículos 2.3, 9.1.in fine, 9.2, 9.5 párrafo final, y 49.5) que sólo son constitucionales si se interpretan como señala la sentencia. De hecho, en el caso del artículo 9.1.in fine, la sentencia rescribe la Ley sin que formalmente se note.

No quisiéramos dedicar mucha extensión a esta sentencia pues ha sido debatida, analizada y criticada desde los más variados puntos 


\section{$046-047$ \\ Debate \\ e Investigación}

La acomodación del PH

al Estado Autonómico.

Regulación normativa, etc.

\section{PH48 - Abril 2004}

de vista y ampliamente comentada en otras páginas de este número. Nos limitaremos a resumir su contenido autonómico, que es lo más predominante. Para la sentencia:

$>$ Los bienes del Patrimonio Histórico forman parte de la cultura de un país y, por ello, del genérico concepto constitucional de "cultura" en el que es posible hallar fundamento para una competencia estatal más amplia y a ello obedece el contenido del artículo 149.2 de la Constitución (F. J. 2).

$>$ Existe una competencia concurrente del Estado y de las Comunidades Autónomas en donde corresponde al Estado la preservación del patrimonio cultural común. Y la integración de la competencia del Patrimonio Histórico en la más general de cultura es la que permite que el Estado dicte la Ley del patrimonio Histórico además de las materias exigidas por el artículo 149.1.28 (F. J. 3).

$>$ Pero todo esto no permite extender indebidamente la competencia estatal que está limitada por las competencias estatuarias (F. J. 3).

$>$ Estado y Comunidades Autónomas tienen competencias concurrentes en la difusión internacional del conocimiento del Patrimonio Histórico, si bien en virtud de títulos diferentes (F. J. 6).

$>$ La noción constitucional de expoliación no debe quedar limitada a su estricto significado gramatical pues limitaría la competencia del Estado a los estrictos ataques físicos y ha de entenderse como un plus de protección respecto de bienes de características especiales y que van destinadas a evitar el incumplimiento de sus funciones como bienes portadores de valores de interés general (F. J. 7)

$>$ En la medida en que la tengan asumida estatutariamente, debe corresponder a las Comunidades Autónomas la competencia para emitir la declaración formal de los Bienes de Interés Cultural y el artículo 9.1 sólo es constitucional si se entiende referido a los bienes sobre los que el Estado es competente (F. J. 10).
$>$ El artículo $49.5^{\circ}$ no excluye la competencia autonómica para declarar los bienes que tienen la consideración de bienes del patrimonio Documental (F. J. 11).

$>$ Los registros e inventarios estatales previstos en la Ley no otorgan por sí solos una competencia al Estado (F. J. 12).

Estas ideas, junto a otras que no tenemos tiempo de señalar, constituyen el contenido de la sentencia, que tuvo dos efectos esenciales. Por un lado, relegislar en materia de declaraciones de Bienes de Interés Cultural y de bienes del Patrimonio Documental hasta el extremo de limitar a casos muy específicos la competencia estatal. En segundo lugar, consolidar la idea de la concurrencia estatal y autonómica en materia de bienes del Patrimonio Histórico. La sentencia restableció las competencias autonómicas que la Ley había negado innecesariamente si bien hay que reconocer que no previó adecuadamente una competencia residual que habría sido necesariamente conservar, con muchas cautelas, al Estado.

Después de esta sentencia, el Tribunal Constitucional volvió a tocar temas competenciales una sola vez: en la sentencia 109/1996, de 13 de junio ${ }^{15}$, si bien el Patrimonio Histórico, sin alcance competencial, fue objeto de otra importante sentencia, la 181/1998, de 17 de septiembre ${ }^{16}$. La sentencia 109/1996, de 13 de junio, zanjó un conflicto de competencia promovido por el Consejo Ejecutivo de la Generalidad de Cataluña frente a una Orden del Ministro de Cultura de 10 de julio de 1989 sobre subvenciones y ayudas económicas a Museos, competencia que la sentencia atribuyó a la Comunidad Autónoma de Cataluña. En este caso el Tribunal empezó estableciendo que al tratarse de Museos que no eran de titularidad estatal, la materia sobre la que recaían las subvenciones correspondía a la Comunidad Autónoma recurrente. Dicho esto, la sentencia recordó que, ello no

\section{Opinión del lector}

\section{La descentralización y los ciudadanos}

\section{Antonio Bellido Blanco}

Museo de Valladolid

El traspaso de competencias en materia de cultura a las Comunidades Autónomas se produjo hace ya un par de décadas. Ha pasado bastante tiempo. Casi el mismo que desde la promulgación de la Ley 16/1985 de PHE, que en su preámbulo destacaba cómo el aprecio de los ciudadanos hacia el patrimonio histórico es lo que determina su valor y su disfrute. Los años transcurridos han ido dejando un buen número de leyes sobre el patrimonio cultural, pero aún cabe preguntarse si la multiplicación de los recursos ha servido para llegar a las personas corrientes y aumentar su sensibilidad. Todas las normas, tanto estatales como autonómicas, mantienen unas pautas muy similares. La regulación que proponen se define en unas pocas líneas básicas:

1. Fórmulas de protección del patrimonio: declaraciones de BIC y otras categorias de bienes protegidos y elaboración de inventarios. 2. Medidas económicas para fomentar la investigación y también la protección y la conservación entre propietarios e inversores.

3. Actuaciones de conservación y tutela: museos, bibliotecas y archivos y arqueologia de gestión.

4. Órganos consultivos e instituciones técnicas.

En general se percibe en estos puntos un relativo alejamiento de los ciudadanos, que a lo sumo tendrán contacto con museos y bibliotecas. Las programaciones de las Administraciones estatal y autonómicas rara vez inciden en los ciudadanos de forma que 
obstante, el artículo 149.2 de la Constitución permitía al Estado llevar actuaciones relacionadas con estos Museos no estatales porque la competencia genérica sobre cultura no, puede ser desplazada sobre la especifica de Museos. Pero, concluia el Tribunal, tampoco la competencia sobre cultura puede convertirse en un título universal que permita toda clase de actuaciones estatales pues hay muchas materias que en el bloque de constitucionalidad tienen un contenido cultural: la competencia sobre cultura no permite al Estado realizar indistintamente las mismas actividades normativas y de ejecución que las Comunidades Autónomas. La aplicación de estas nociones y la propia doctrina del Tribunal sobre subvenciones llevó a la sentencia a la conclusión de que el Estado, ex artículo 149.2, puede consignar subvenciones de fomento en sus Presupuestos Generales del Estado a favor de los Museos de titularidad autonómica especificando de forma global su afectación o destino pero sin reservarse competencias de gestión.

Ésta es la jurisprudencia constitucional en materia de competencias sobre Patrimonio Histórico. No es amplia pero la sentencia 17/1991, de 31 de julio, tiene por sí sola valor legislativo de modo que llena todo el campo normativo del período.

\section{La legislación autonómica}

Si antes de febrero de 1991 señalábamos dos Leyes autonómicas generales, las de Castilla-La Mancha y del País Vasco, este período va a conocer la eclosión de la legislación autonómica general sin renunciar a las de carácter sectorial. Más que señalar las Leyes que se aprobaron apuntemos las Comunidades Autónomas que aún hoy no han aprobado Leyes generales: La Rioja, la Región de Murcia y la Comunidad Foral de Navarra. Salvo estos tres territorios, todos los restantes han ido aprobando sus Leyes generales: desde la Ley 1/1991, de 3 de julio, del
Patrimonio Histórico de Andalucía, que fue la primera del período, hasta la Ley 12/2002, de 11 de julio, de Patrimonio Cultural de Castilla y León, que ha sido la última en aprobarse, doce Leyes autonómicas de régimen general del Patrimonio Histórico han transformado totalmente el panorama del Derecho español de los bienes culturales.

Además, no han dejado de aprobarse Leyes sectoriales cuya enumeración se haría larga ${ }^{17}$ aunque conviene destacar que sólo la Comunidad Foral de Navarra carece de normas de rango legislativo.

Esta proliferación obliga a replantearse el papel que hoy debe desempeñar la Ley estatal, acentuando el cumplimiento de sus estrictas competencias constitucionales pues la gestión ordinaria de las políticas públicas de protección y de difusión de los bienes culturales ha sido objeto de esta amplisima regulación jurídica. En todo caso, hoy por hoy el Derecho del Patrimonio Histórico Español es una de las ramas más frondosas del ordenamiento.

\section{La nueva -y rica- producción doctrinal}

Apuntábamos más arriba que la tesis doctoral de la profesora Barrero Rodríguez abrió el ciclo de las tesis doctorales que con gran rigor y extensión han dado, en pocos años, un importantísimo impulso al Derecho del Patrimonio Histórico, impulso al que quizá contribuyó la creación del anuario Patrimonio Cultural y Derecho cuyo primer número apareció en 1997. Debemos señalar las dos grandes tesis del periodo. En primer lugar se publicó El Patrimonio Histórico. Destino público y valor cultural de la profesor María del Rosario Alonso Ibáñez (Ed. Civitas-Universidad de Oviedo, Madrid, 1992) que tenía el mérito de estudiar la posición de la Ley estatal como norma delimitadora de competencias así como su fundamento constitucional, un capítulo de gran valor éstos sean capaces de apreciarlo. Donde más llega a notarlo el ciudadano es en aquello que le sirve para su tiempo de ocio, como la creación de infraestructuras y recursos turísticos. $Y$ dentro de este apartado de servicios, su papel queda reducido al de un mero usuario, con escasa capacidad de intervención.

Para encontrar el contacto cercano con la calle hay que descender a un nivel inferior. La mayor proximidad se alcanza en las administraciones locales. Por un lado trabajan en la organización de espectáculos (teatro, cine, danza, música...) y en el montaje de museos y exposiciones más vinculados por su temática a cada ciudad o pueblo. También tienen un papel muy relevante en la protección del patrimonio a través de las intervenciones urbanisticas.

Los proyectos locales pueden atender con mayor acierto y rapidez las demandas de la gente. Del mismo modo, en el caso de que se alejen de las inquietudes y deseos populares, lo notarán mucho antes $\mathrm{y}$, dados sus limitados recursos económicos, podrá llegar el caso en que el fracaso les obligue a cambiar sus objetivos 0 a desistir de sus planes.

Otro estadio más básico de intervención ciudadana viene dado por el asociacionismo. La iniciativa de unos pocos individuos puede servir para implicar a sectores más amplios de la sociedad. Desde esta plataforma se plantean iniciativas de todo tipo relacionadas con la protección del Patrimonio Cultural, su promoción y la divulgación de sus valores, actuando a través de inversiones económicas y de trabajo, movilizaciones (manifestaciones, escritos, boicoteos, recogida de firmas...) y publicaciones y actos públicos.

La realidad es que todavia la descentralización ha alcanzado poco a estos niveles inferiores. Falta proteger y desarrollar todas las posibilidades, delegar responsabilidades, crear órganos de participación y, al mismo tiempo, oportunos sistemas de control. Todavia los ciudadanos no han encontrado los cauces para dejar oír su voz en los temas que atañen al Patrimonio Cultural y que sea tenida en consideración. 


\section{8- 049 \\ Debate \\ e Investigación}

La acomodación del PH

al Estado Autonómico.

Regulación normativa, etc.

\section{PH48 - Abril 2004}

por el esfuerzo de interpretar la Ley 16/1985, de 25 de junio, en esa perspectiva competencial (págs. 61-121). Poco después se publicó la tesis del profesor Juan Manuel Alegre Ávila Evolución y régimen jurídico del Patrimonio Histórico (Ministerio de Cultura, Madrid, 1994) donde se insertaba un muy extenso capitulo final (en realidad, constituía por sí solo una monografía) sobre la distribución de competencias en la materia incluyendo un pormenorizado análisis de la sentencia 17/1991, de 31 de enero (págs. 637-784). Con estas dos tesis, el arcano de la distribución de competencias quedó bastante aclarado.

En esa misma línea de aproximación general a la materia, en los Estudios sobre la Constitución Española. Homenaje al profesor Eduardo García de Enterría (Ed. Civitas, Madrid, 1991) encontramos varios trabajos que tratan el reparto competencial: "Concepto y otros aspectos del Patrimonio Cultural en la Constitución", de Jesus Prieto de Pedro (t. II, págs. 1551-1572), y "El postulado constitucional de la promoción y conservación del patrimonio histórico y artístico", de Alfonso Pérez Moreno (t. II, págs. 1621-1641) ${ }^{18}$.

Otro campo que conviene señalar es el de las publicaciones monográficamente dedicadas a la distribución competencial de los bienes culturales en perspectiva general, no local. El primer trabajo que debe reseñarse es el de Josu Erkoreka "Reflexiones sobre el alcance y contenido de la competencia que el artículo 149.1.28 de la Constitución reserva al Estado en materia de Patrimonio cultural, artístico y monumental" (Revista Vasca de Administración Pública, núm. 41, abril 1995, págs. 97-141) que pone en cuestión la posibilidad de una Ley estatal. Tras este trabajo vino el de Alfredo Pérez de Armiñán y de la Serna Las competencias del Estado sobre el Patrimonio Histórico Español en la Constitución de 1978 (Ed. Civitas, Madrid, 1997) que era un muy cuidadoso y sutil estudio de la distribución de competencias. Posteriormente, Patrimonio Cultural y Derecho publicó dos trabajos que Ilegaban a conclusiones diferentes: el de Enrique Linde Paniagua titulado "Los museos, bibliotecas y archivos de titularidad estatal" (núm. 2, 1998, págs. 81-90) y en sentido opuesto, el de Javier García Fernández "El régimen jurídico de los archivos, bibliotecas y museos de titularidad estatal conforme a la Constitución" (núm. 3, 1999, págs. 179-199) ${ }^{19}$.

\section{Conclusiones}

A lo largo de esta rápida carrera, hemos pretendido presentar al lector cual es hoy el Derecho autonómico de los bienes culturales y el punto en el comenzamos. Ha sido un recorrido largo y especialmente complejo pues partíamos del modelo centralizador más imaginable y hemos acabado en una situación absolutamente descentralizado. Este tipo de evolución no se produce nunca sin tensiones (que las ha habido) y sin algún punto de insatisfacción (¿debería estar el Estado tan desapoderado como hiperapoderado estaba antes de la sentencia de 1991?). Pero, como dice el profesor Prieto de Pedro, el Patrimonio Histórico nunca ha estado tan protegido y eso es la obra de una legislación profusa, a veces excesiva, a veces contradictoria, pero que ha señalado una senda para la protección de estos bienes. El recorrido ha sido complejo pero no inútil.

${ }^{1}$ Era un ordenamiento tan extenso que la mejor compilación que se publicó por aquel entonces, justo cuando se estaba tramitando el proyecto constitucional (Patrimonio Artístico, Archivos y Museos, Ministerio de Cultura, Madrid, 1978) alcanzaba ya 1144 páginas.

${ }^{2}$ Lo fue por el Real Decreto 1558/1977, de 4 de julio, por el que se reestructuran determinados órganos de la Administración Central del Estado. En este Real Decreto todavía se denominaba Ministerio de Cultura y Bienestar

${ }^{3}$ Este precepto, sin sufrir grandes reformas de fondo, fue profundamente modificado en la forma por la Ley 4/1999, de 8 de enero, que incluso provocó su renumeración pues en su origen este contenido correspondia al artículo 26

${ }^{4}$ También este precepto, sin sufrir grandes reformas de fondo, fue profundamente modificado en la forma por la Ley 4/1999, de 8 de enero, que incluso llegó a renumerarse pues en su origen este contenido correspondia al artículo 28.

${ }^{5}$ Todavía se celebraron Convenios para la gestión de los Archivos, Bibliotecas y Museos de titularidad estatal: desde la muy menor Resolución de 22 de abril de 1987 por la que se da publicidad al acta suscrita entre la Administración del Estado y la Comunidad valenciana modificando el anexo al Convenio de gestión de Bibliotecas de titularidad estatal suscrito con fecha 24 de septiembre de 1984, hasta (último que tengo reseñado) la Resolución de 1 de marzo de 1999 por la que se da publicidad al Convenio suscrito entre el Ministerio de Educación y Cultura y la Comunidad Autónoma de Extremadura, que modifica el anexo del Convenio de gestión de $\mathrm{Bi}$ bliotecas de titularidad estatal de fecha 6 de abril de 1989, al incluirse en el mismo la Biblioteca Pública del Estado en Mérida.

${ }^{6}$ Todas las Provincias salvo en la Comunidad Autónoma del País Vasco, Comunidad Autónoma de Cataluña, Comunidad Foral de Navarra y Comunidad de Madrid.

${ }^{7}$ Recogida en Jurisprudencia constitucional, t. II, págs. 375-390.

${ }^{8}$ Recogida en Jurisprudencia constitucional, t. VII, págs. 70-77.

${ }^{9}$ Recogida en Jurisprudencia constitucional, t. XIII, págs. 289-307.

${ }^{10}$ Real Decreto 111/1986, de 10 de enero, de desarrollo parcial de la Ley 16/1985, de 25 de junio, del Patrimonio Histórico Español; Real Decreto 620/1987, de 10 de abril, por el que se aprueba el Reglamento de Museos de Titularidad Estatal y del Sistema Español de Museos; y Real Decreto 582/1989, de 19 de mayo, por el que se aprueba el Reglamento de Bibliotecas Públicas del Estado y del Sistema Español de Bibliotecas.

${ }^{11}$ Recogida en Jurisprudencia constitucional, t. XXI, págs. 170-179.

${ }^{12}$ Recogida en Jurisprudencia constitucional, t. XVIII, págs. 490-502.

${ }^{13}$ Recogida en Jurisprudencia constitucional, t. XXV, págs. 123-137.

${ }^{14}$ Recogida en Jurisprudencia constitucional, t. XXIX, págs. 151-179

${ }^{15}$ Recogida en Jurisprudencia constitucional, t. XLV, págs. 403-419.

${ }^{16}$ Recogida en Jurisprudencia constitucional, t. LII, págs. 47-68.

${ }^{17}$ En el periodo que va desde enero de 1991 hasta hoy (febrero de 2004) se han aprobado seis Leyes de Museos, cuatro Leyes de Bibliotecas, seis Leyes de Patrimonio Documental y Archivos, una Ley de fomento, dos Leyes de Parques Culturales o Arqueológicos y dos Leyes sobre protección de bienes inmuebles.

${ }^{18}$ Situado entre ambos artículos había un trabajo de Juan Manuel Alegre Ávila pero apenas tocaba los aspectos competenciales de la materia.

${ }^{19}$ Además, a lo largo de este período se han publicado muchos y excelentes trabajos sobre la legislación de bienes culturales en varias Comunidades Autónomas (Aragón, Cantabria, Comunidad Valenciana) sobre los que no podemos detenernos. 